\title{
Analogy between momentum and heat transfer in liquid-solid fluidized beds
}

\author{
Darko Jaćimovski ${ }^{\mathrm{a}}$, Radmila Garić-Grulović ${ }^{\mathrm{a}, *}$, Željko Grbavčić ${ }^{\mathrm{b}}$, Nevenka Bošković Vragolović ${ }^{\mathrm{b}}$ \\ a Institute for Chemistry, Technology and Metallurgy, University of Belgrade, Belgrade, Serbia \\ ${ }^{\mathrm{b}}$ Faculty of Technology and Metallurgy, University of Belgrade, Belgrade, Serbia
}

\section{A R T I C L E I N F O}

Article history:

Received 4 July 2014

Received in revised form 5 November 2014

Accepted 7 November 2014

Available online 15 November 2014

\section{Keywords:}

Fluidized bed

Momentum transfer

Heat transfer

Mass transfer

Analogy

\begin{abstract}
A B S T R A C T
Wall-to-bed heat transfer in particulate fluidized beds of spherical particles was studied. Experiments were performed using spherical glass particles of $0.80-2.98 \mathrm{~mm}$ in diameter with water in a $25.4 \mathrm{~mm}$ I.D. copper tube equipped with a steam jacket.

Heat transfer data related to the fluid-particle interphase drag coefficient were obtained and compared with previous results for wall-to-bed mass transfer in fluidized beds [Bošković et al., Powder Technol., 79 (1994) 217]. All the data for momentum, heat and mass transfer in particulate fluidized beds of spherical particles, showed the existence of an analogy among these three phenomena.
\end{abstract}

(C) 2014 Elsevier B.V. All rights reserved.
Heat transfer in liquid-solid systems is a very important parameter to be considered in the design of equipment for different industrial applications. The design of equipment with fluidized beds is mainly based on the knowledge of the hydrodynamics and heat transfer between wall and fluidized beds. Numerous studies on wall-to-liquid heat transfer in particulate fluidized beds have been realized [1-6]. In these studies, the influence of different parameters, such as liquid velocity, particles size and voidage on heat transfer in fluidized beds was investigated.

The subject of the present research was the effect of particles on the wall-to-bed heat transfer. An attempt was made to establish analogy between heat transfer coefficients and fluid-particle interphase drag coefficient.

In a previous study, Bošković et al. [7] found that an analogy between mass and momentum transfer in liquid-solid fluidized beds exists. In addition, the dimensionless mass transfer factor in liquid-fluidized beds of active and inert particles and the dimensionless drag coefficient [8] were shown to be the same.

$j_{D}^{*}=\beta^{*}$

where $j_{D}^{*}$ and $\beta^{*}$ are given by,

$j_{D}^{*}=\frac{j_{D}-j_{D_{1}}}{j_{D_{m f}}-j_{D_{1}}}$

\footnotetext{
* Corresponding author. Tel.: + 381113370 500; fax: + 381113370408 .

E-mail address: garic@tmf.bg.ac.rs (R. Garić-Grulović).
}

$$
\beta^{*}=\frac{\beta}{\beta_{m f}}=1-C_{2}+\frac{1}{\lambda} \sqrt{1-\left(\lambda \frac{\varepsilon-\varepsilon_{m f}}{1-\varepsilon_{m f}}+C_{1}\right)^{2}} .
$$

Wall-to-bed heat transfer in particulate fluidized beds of spherical particles was studied. Experiments were performed using spherical glass particles of $0.80,1.11,1.94$ and $2.98 \mathrm{~mm}$ in diameter that were fluidized with water in a $25.4 \mathrm{~mm}$ I.D. copper tube equipped with a steam jacket. The schematic diagram of the experimental systems is shown in Fig. 1.

The fluid bed (a, Fig. 1) was the 27.4/25.4 mm OD/ID, $1360 \mathrm{~mm}$ long copper tube, equipped with a $700 \mathrm{~mm}$ long steam jacket (b). The heating section (b) was located far enough ( $320 \mathrm{~mm}$ ) from the inlet nozzle (d) of the fluid bed. Water was introduced at the bottom of the bed.

The pressure gradient was measured using piezometers (i) and temperature was measured using $\mathrm{Ni}-\mathrm{Cr}$ thermocouples. The wall temperature was determined at two points, at the inlet and at the exit of the heating zone; $\mathrm{T}_{01}$ and $\mathrm{T}_{02}$. The junction points were filled with tin at about $0.2 \mathrm{~mm}$ from the inside of the tube wall, as shown schematically in Fig. 1 (detail A). The temperature of the fluidized bed was measured with thermocouples located along the tube axis $\left(\mathrm{T}_{\infty 1}, \mathrm{~T}_{\infty 2}\right)$. It was assumed that at the inlet and at the outlet of the heating zone, the particles and the fluid had the same temperature [2]. The heat transfer coefficient in the fluidized bed was calculated as [3]:

$\alpha=\frac{G_{f} c_{p f}\left(T_{\infty 2}-T_{\infty 1}\right)}{D_{c} \pi L_{H} \Delta T_{\ln }}$. 


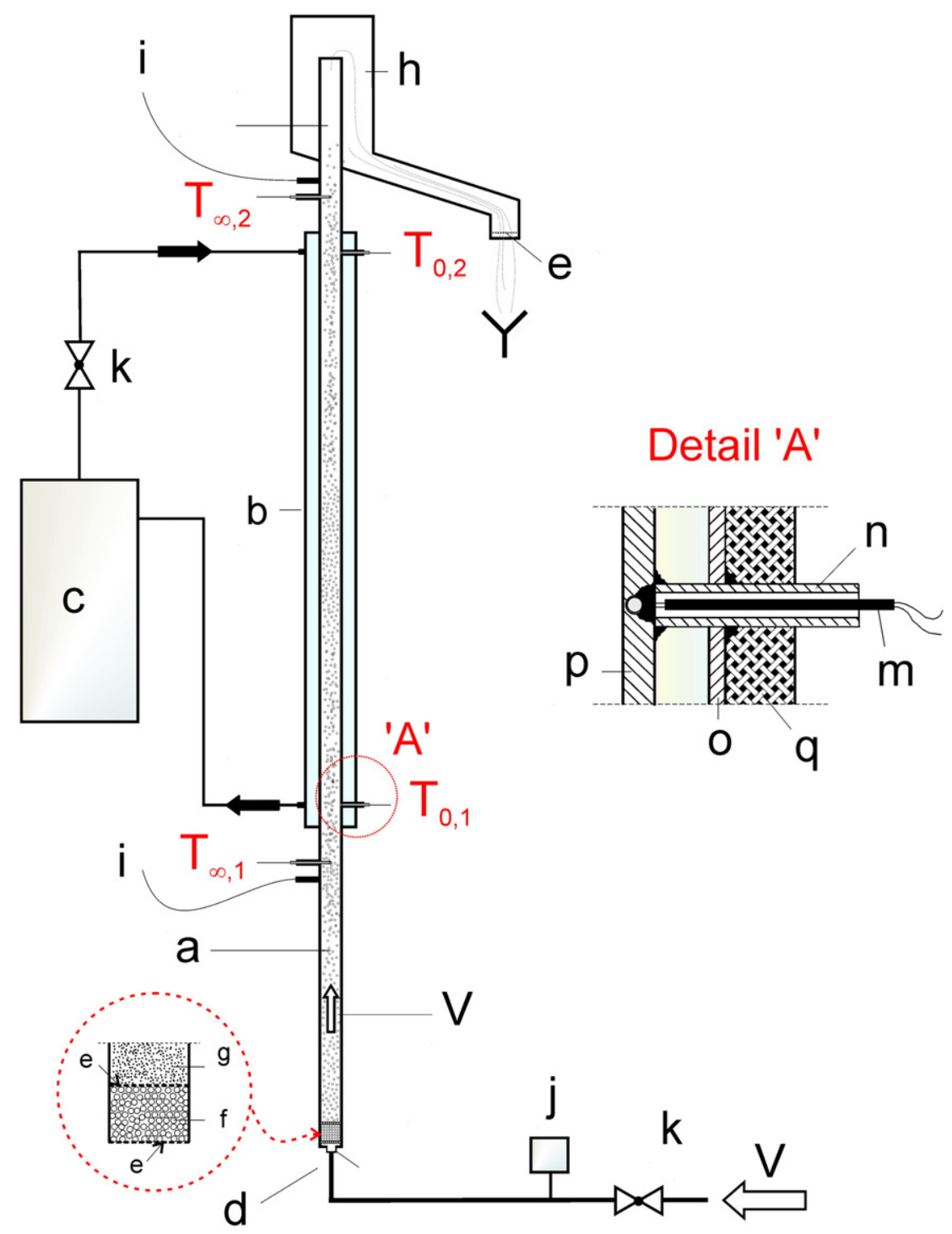

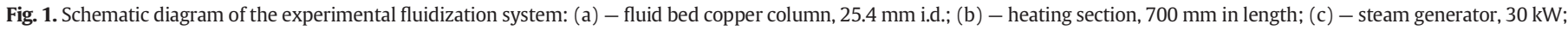

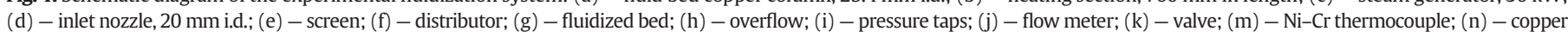
tube 8/6 mm; (o) - jacket wall; (p) - column wall; (q) - thermal insulation; $\mathrm{V}$ - inlet flow rate.

The mean logarithmic temperature difference in Eq. (4) is defined as:

$\Delta T_{\ln }=\frac{\left(T_{0,2}-T_{\infty, 2}\right)-\left(T_{0,1}-T_{\infty, 1}\right)}{\ln \frac{\left(T_{0,2}-T_{\infty, 2}\right)}{\left(T_{0,1}-T_{\infty, 1}\right)}}$.

A total of 156 data points for heat transfer coefficients were collected in the experimental runs. The characteristics of the particles and the employed range of experimental conditions are given in Table 1. Water was used as the fluidizing medium, and its characteristics were determined as temperature dependencies [9]: $\mu=\mathrm{f}\left(\mathrm{T}_{\mathrm{m}}\right), \rho_{\mathrm{f}}=\mathrm{f}\left(\mathrm{T}_{\mathrm{m}}\right)$ and $\mathrm{c}_{\mathrm{pf}}=\mathrm{f}\left(\mathrm{T}_{\mathrm{m}}\right)$.

The variation in the wall-to-bed heat transfer factor and the dimensionless drag coefficient in dependence on the bed voidage for the $2.98 \mathrm{~mm}$ diameter particles are illustrated in Fig. 2 from which it is evident that the heat transfer factor decreased with increasing bed voidage. It could be registered that this plot is very similar to the variation of the dimensionless fluid-particle interphase drag coefficient with bed voidage.
The present experimental data for heat transfer factor, analogous to the work of Bošković et al. [7], can be represented as (Eq. (1)):

$j_{H}^{*}=\beta^{*}$

where $j_{H}^{*}$ is

$j_{H}^{*}=\frac{j_{H}-j_{H_{1}}}{j_{H_{m f}}-j_{H_{1}}}$.

Table 1

Particle characteristics and range of experimental conditions (at 293.15 K).

\begin{tabular}{lllll}
\hline $\mathrm{d}_{\mathrm{p}}(\mathrm{mm})$ & 0.80 & 1.11 & 1.94 & 2.98 \\
$\rho_{\mathrm{p}}\left(\mathrm{kg} / \mathrm{m}^{3}\right)$ & 2923 & 2641 & 2507 & 2509 \\
$\mathrm{U}_{\mathrm{t}}(\mathrm{m} / \mathrm{s})^{\mathrm{a}}$ & 0.148 & 0.185 & 0.299 & 0.370 \\
$\mathrm{U}_{\mathrm{mf}}, \mathrm{m} / \mathrm{s}^{\mathrm{a}}$ & 0.008 & 0.013 & 0.028 & 0.043 \\
$\mathrm{U} / \mathrm{U}_{\mathrm{mf}}$ & $5.224-17.401$ & $3.797-9.417$ & $1.679-6.311$ & $1.883-4.080$ \\
$\varepsilon_{\mathrm{mf}}$ & 0.398 & 0.416 & 0.447 & 0.462 \\
$\varepsilon / \varepsilon_{\mathrm{mf}}$ & $1.638-2.393$ & $1.569-2.175$ & $1.126-2.039$ & $1.319-1.883$ \\
\hline
\end{tabular}

a Calculated from Kunii and Levenspiel [10]. 


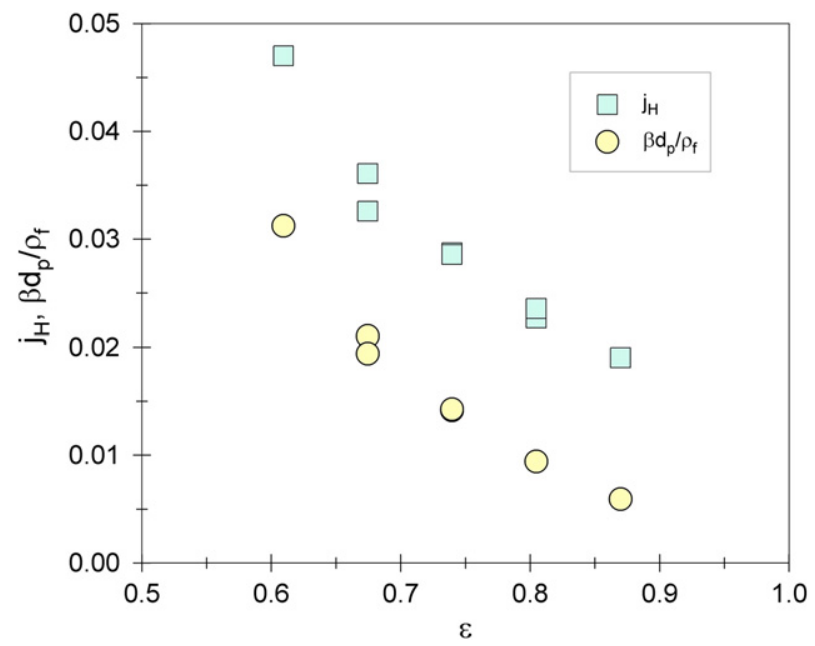

Fig. 2. The experimental data for the heat transfer factor and dimensionless drag coefficient vs. voidage, for a fluidized bed $\left(\mathrm{d}_{\mathrm{p}}=2.98 \mathrm{~mm}\right)$.

If Eq. (3) is substituted into Eq. (7) then:

$\frac{j_{H}-j_{H_{1}}}{j_{H_{m f}}-j_{H_{1}}}=1-C_{2}+\frac{1}{\lambda}\left[\sqrt{1-\left(\lambda \frac{\varepsilon-\varepsilon_{m f}}{1-\varepsilon_{m f}}+C_{1}\right)^{2}}\right]^{1 / 2}$.

The data for the heat transfer factor at the terminal velocity, $j_{H_{1}}$, and for the heat transfer factor at minimum fluidization velocity, $j_{H_{m}}$, could be acquired by extrapolating experimental data that are given as the dependency of the heat transfer factor, $\mathrm{j}_{\mathrm{H}}$, on the dimensionless fluidparticle interphase drag coefficient, $\beta^{*}$. The parameters $j_{H_{1}}$ and $j_{H_{m f}}$ are determined for both: $\beta / \beta_{\mathrm{mf}}=0$ (terminal velocity) and for $\beta / \beta_{\mathrm{mf}}=1$ (minimum fluidization), as can be seen in Fig. 3.

All the data for the dimensionless $j_{H}^{*}$ factor acquired in the present experimental runs, the experimental data for the dimensionless $j_{D}^{*}$ factor from the previous work of Bošković et al. [7], and the data for the dimensionless fluid-particle interphase drag coefficient $\beta^{*}$ are plotted against the dimensionless bed voidage $\varepsilon^{*}=\left(\varepsilon-\varepsilon_{m f}\right) /\left(1-\varepsilon_{m f}\right)$ in Fig. 4.

As can be seen from Fig. 4 , the values of $j_{H}^{*}, j_{D}^{*}$ and $\beta^{*}$ are practically the same in the range of the investigated conditions, clearly indicating an analogy among these phenomena. From all the presented results, it

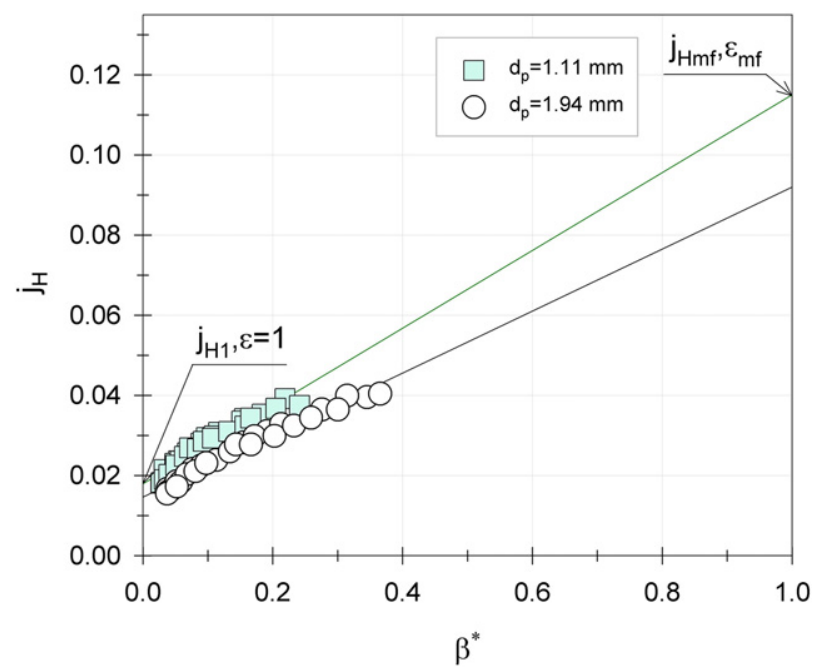

Fig. 3. Determination of $\mathrm{j}_{\mathrm{H}}$ at the minimum fluidization and terminal using the relationship $\mathrm{j}_{\mathrm{H}}$ Vs. $\beta^{*}$.

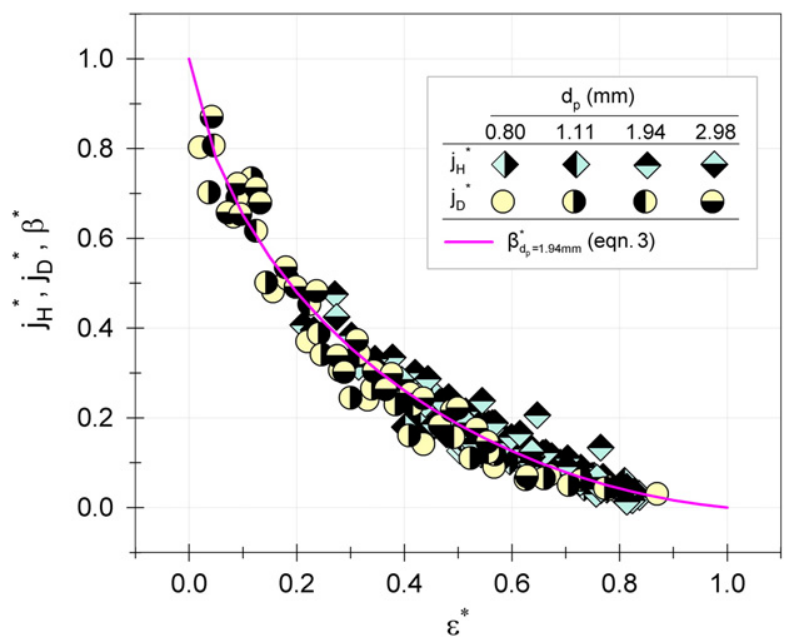

Fig. 4. A comparison of the data for heat transfer against mass transfer [7] and the friction factor in a fluidized bed.

could be concluded that all data for fluidized bed could be described by the following correlation:

$j_{H}^{*}=j_{D}^{*}=\beta^{*}$.

The mean absolute deviation between the experimental data of the dimensionless heat transfer factor and Eq. (3) is $18.33 \%$.

The analogy established in this work enables the application of the proposed model for the determination of the fluid-particle interphase drag coefficient (Eq. (3)) and of heat and mass transfer factors in liquid-solid fluidized beds (Eq. (9)).

\section{Nomenclature}

$\mathrm{C}_{1} \quad$ variational constant in Eq. (3)

$\mathrm{C}_{2} \quad$ variational constant in Eq. (3)

$\mathrm{c}_{\mathrm{pf}} \quad$ specific heat of fluid, $\mathrm{J} /(\mathrm{kg} \mathrm{K})$

$\mathrm{d}_{\mathrm{p}} \quad$ particle diameter, $\mathrm{m}$

$\mathrm{D}_{\mathrm{c}} \quad$ column diameter, $\mathrm{m}$

$\mathrm{G}_{\mathrm{f}} \quad$ fluid mass flowrate in the column, $\mathrm{kg} / \mathrm{s}$

$j_{H} \quad \mathrm{Nu} / \operatorname{Re} \operatorname{Pr}^{1 / 3}$, heat transfer factor

$j_{H_{1}} \quad$ heat transfer factor at the terminal velocity

$j_{H_{m f}} \quad$ heat transfer factor at minimum fluidization

$j_{H}^{*} \quad\left(j_{H}-j_{H_{1}}\right) /\left(j_{H_{m f}}-j_{H_{1}}\right)$, dimensionless $\mathrm{j}_{\mathrm{H}}$ factor

$j_{D} \quad \mathrm{Sh} / \operatorname{ReSc}^{1 / 3}$, mass transfer factor

$j_{D_{1}} \quad$ mass transfer factor at the terminal velocity

$j_{D_{m f}} \quad$ mass transfer factor at minimum fluidization

$j_{D}^{*} \quad\left(j_{D}-j_{D_{1}}\right) /\left(j_{D_{m f}}-j_{D_{1}}\right)$, dimensionless $\mathrm{j}_{\mathrm{D}}$ factor

$\mathrm{L}_{\mathrm{H}} \quad$ length of heating zone, $\mathrm{m}$

$\mathrm{T}$ temperature $(\mathrm{K})$

$\mathrm{T}_{0} \quad$ temperature of the column wall $(\mathrm{K})$

$\mathrm{T}_{\infty} \quad$ fluid temperature $(\mathrm{K})$

$\mathrm{T}_{\mathrm{m}} \quad\left(T_{\infty, 1}+T_{\infty, 2}\right) / 2$, means temperature $(\mathrm{K})$

$\mathrm{U}_{\mathrm{t}} \quad$ terminal velocity, $\mathrm{m} / \mathrm{s}$

$\mathrm{U}_{\mathrm{mf}} \quad$ superficial fluid velocity at minimum fluidization, $\mathrm{m} / \mathrm{s}$

$\mathrm{V} \quad$ water flowrate at the column inlet $\left(\mathrm{m}^{3} / \mathrm{s}\right)$ (Fig. 1)

\section{Greek letters}

$\alpha \quad$ heat transfer coefficient, $\mathrm{W} /\left(\mathrm{m}^{2} \mathrm{~K}\right)$

$\beta \quad$ fluid-particle interphase drag coefficient, $\mathrm{kg} / \mathrm{m}^{4}$

$\beta_{\mathrm{mf}} \quad$ fluid-particle interphase drag coefficient at minimum fluidization, $\mathrm{kg} / \mathrm{m}^{4}$

$\beta^{*} \quad \beta / \beta_{\mathrm{mf}}$, dimensionless fluid-particle interphase drag coefficient $\varepsilon \quad$ averaged voidage in the fluidized bed 
$\varepsilon_{\mathrm{mf}} \quad$ voidage at minimum fluidization

$\varepsilon^{*} \quad\left(\varepsilon-\varepsilon_{\mathrm{mf}}\right) /\left(1-\varepsilon_{\mathrm{mf}}\right)$, dimensionless bed voidage

$\lambda \quad$ variational constant in Eq. (3)

$\mu \quad$ fluid viscosity, $\mathrm{Pa} \cdot \mathrm{s}$

$\rho_{\mathrm{f}} \quad$ fluid density, $\mathrm{kg} / \mathrm{m}^{3}$

$\begin{array}{ll}\rho_{\mathrm{p}} & \text { particle density, } \mathrm{kg} / \mathrm{m}^{3} \\ \delta_{\text {sr. }} & \text { the mean absolute deviation }\end{array}\left(=100 \cdot \frac{1}{n} \sum_{1}^{n} \frac{\left|\Gamma_{\text {exp. }}-\Gamma_{\text {calc. }}\right|}{\Gamma_{\text {calc. }}}\right), \%$

\section{Acknowledgment}

Financial support of the Serbian Ministry of Education and Science (Project No. ON172022) is gratefully acknowledged.

\section{References}

[1] K. Muroyama, M. Fukuma, A. Yasunishi, Wall-to-bed heat transfer in liquid-solid and gas-liquid-solid fluidized beds part I: liquid-solid fluidized beds, Can. J. Chem. Eng. 64 (1986) 399-408.

[2] J.S.M. Botterill, Fluid-bed Heat Transfer, Academic Press, London, 1975. (315 pages).
[3] R. Garić-Grulović, N. Bošković-Vragolović, Ž. Grbavčić, Z. Arsenijević, Wall-to-bed heat transfer in vertical hydraulic transport and in particulate fluidized beds, Int. J. Heat Mass Transfer 51 (2008) 5942-5948.

[4] K. Hashizume, Y. Kimura, S. Morita, Analogy between pressure drop and heat transfer in liquid-solid circulating fluidized beds, Heat Tran. Asian Res. 38 (2009) 183-193.

[5] S. Wang, Y. Zhao, X. Li, L. Liu, L. Wei, Y. Liu, J. Gao, Study of hydrodynamic characteristics of particles in liquid-solid fluidized bed with modified drag model based on EMMS, Adv. Powder Technol. 25 (2014) 1103-1110.

[6] S. Wang, J. Sun, Q. Yang, Y. Zhao, J. Gao, Y. Liu, Numerical simulation of flow behavior of particles in an inverse liquid-solid fluidized bed, Powder Technol. 261 (2014) 14-21.

[7] N. Bošković, Ž.B. Grbavčić, D.V. Vuković, M. Marković-Grbavčić, Mass transfer between fluid and immersed surfaces in liquid fluidized beds of coarse spherical inert particles, Powder Technol. 79 (1994) 217-225.

[8] Ž.B. Grbavčić, D.V. Vuković, R.V. Garić, Dž.E. Hadžismajlović, S. Jovanović, H. Littman, H. Morgan, Variational model for prediction fluid-particle interphase drag coefficient and particulate expansion of fluidized and sedimenting beds, Powder Technol. 68 (1991) 199-211.

[9] R. Perry, D. Green, J. Maloney, Perry's Chemical Engineers' Handbook, Mc Graw-Hills, New York, 1997.

[10] D. Kunii, O. Levenspiel, Fluidization Engineering, J. Wiley, New York, 1969. 